\title{
$\mathrm{UNLV}||_{\text {LIBRARIES }}^{\mathrm{UNIVRSTY}}$
}

Mechanical Engineering Faculty Publications

Mechanical Engineering

8-15-2009

\section{Doppler Broadening Analysis of Steel Specimens Using Accelerator Based In Situ Pair Production}

\author{
V. Makarashvili \\ Idaho State University \\ Douglas P. Wells \\ Idaho State University \\ Ajit K. Roy \\ University of Nevada, Las Vegas, aroy@unlv.nevada.edu
}

Follow this and additional works at: https://digitalscholarship.unlv.edu/me_fac_articles

Part of the Materials Science and Engineering Commons, Mechanical Engineering Commons, and the Other Engineering Science and Materials Commons

\section{Repository Citation}

Makarashvili, V., Wells, D. P., Roy, A. K. (2009). Doppler Broadening Analysis of Steel Specimens Using Accelerator Based In Situ Pair Production. AIP Conference Proceedings, 1099 900-903. American Institute of Physics.

https://digitalscholarship.unlv.edu/me_fac_articles/531

This Conference Proceeding is protected by copyright and/or related rights. It has been brought to you by Digital Scholarship@UNLV with permission from the rights-holder(s). You are free to use this Conference Proceeding in any way that is permitted by the copyright and related rights legislation that applies to your use. For other uses you need to obtain permission from the rights-holder(s) directly, unless additional rights are indicated by a Creative Commons license in the record and/or on the work itself.

This Conference Proceeding has been accepted for inclusion in Mechanical Engineering Faculty Publications by an authorized administrator of Digital Scholarship@UNLV. For more information, please contact

digitalscholarship@unlv.edu. 


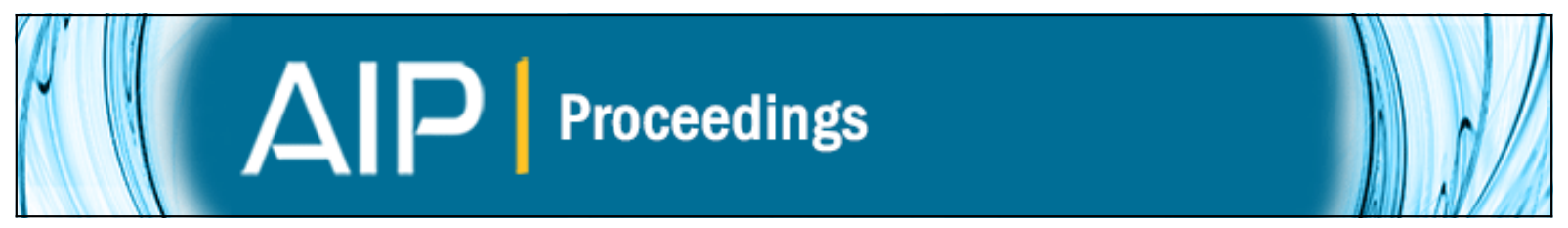

Doppler Broadening Analysis of Steel Specimens Using Accelerator Based In Situ Pair Production

V. Makarashvili, D. P. Wells, and A. K. Roy

Citation: AIP Conference Proceedings 1099, 900 (2009); doi: 10.1063/1.3120185

View online: http://dx.doi.org/10.1063/1.3120185

View Table of Contents: http://scitation.aip.org/content/aip/proceeding/aipcp/1099?ver=pdfcov

Published by the AIP Publishing 


\title{
Doppler Broadening Analysis of Steel Specimens Using Accelerator Based In Situ Pair Production
}

\author{
V. Makarashvili ${ }^{1}$, D.P. Wells ${ }^{1}$ and A.K. Roy ${ }^{2}$ \\ ${ }^{1}$ Department of Physics, Idaho State University, Campus Box 8106, Pocatello, ID 83209 USA \\ ${ }^{2}$ Department of Mechanical Engineering, University of Nevada Las Vegas, 4505 Maryland Parkway, Las Vegas \\ NV 89154 USA
}

\begin{abstract}
Positron Annihilation Spectroscopy (PAS) techniques can be utilized as a sensitive probe of defects in materials. Studying these microscopic defects is very important for a number of industries in order to predict material failure or structural integrity. We have been developing gamma-induced pair-production techniques to produce positrons in thick samples $\left(\sim 4-40 \mathrm{~g} / \mathrm{cm}^{2}\right.$, or $\sim 0.5-5 \mathrm{~cm}$ in steel $)$. These techniques are called 'Accelerator-based Gamma-induced Positron Annihilation Spectroscopy' (AG-PAS). We have begun testing the capabilities of this technique for imaging of defect densities in thick structural materials. As a first step, a linear accelerator (LINAC) was employed to produce photon beams by stopping $15 \mathrm{MeV}$ electrons in a $1 \mathrm{~mm}$ thick tungsten converter. The accelerator is capable of operating with 30-60 ns pulse width, up to $200 \mathrm{~mA}$ peak current at $1 \mathrm{kHz}$ repetition rate. The highly collimated bremsstrahlung beam impinged upon our steel tensile specimens, after traveling through a $1.2 \mathrm{~m}$ thick concrete wall. Annihilation radiation was detected by a well-shielded and collimated high-purity germanium detector (HPGe). Conventional Doppler broadening spectrometry (DBS) was performed to determine $S, W$ and $T$ parameters for our samples.
\end{abstract}

Keywords: positron annihilation, Doppler broadening, defects in metals, defect imaging, steel specimens PACS: $71.60 .+\mathrm{z}, 71.55 .-\mathrm{i}, 78.70 . \mathrm{Bj}$

\section{INTRODUCTION}

Doppler broadening analysis of the $511 \mathrm{keV}$ annihilation peak is known to be a valuable tool to study electron momentum-density distribution at the annihilation site and consequently gain information about microscopic defects (vacancies, dislocations, etc...) in different materials [1]. Detecting these kinds of microscopic defects is very important for a number of industries in order to predict material failure or structural integrity. Positron Annihilation Spectroscopy (PAS) techniques performed with conventional radioactive sources or positron beams are limited to depth that probe only up to a few hundred $\mu \mathrm{m}$ in solids because of the low penetrability of positrons in the $\mathrm{keV}$ range [2-3]. We have been developing gammainduced pair-production techniques to produce positrons in thick samples $\left(\sim 4-40 \mathrm{~g} / \mathrm{cm}^{2}\right.$, or $\sim 0.5-5$ $\mathrm{cm}$ in steel). These techniques are called 'Acceleratorbased Gamma-induced Positron Annihilation Spectroscopy' (AG-PAS). AG-PAS employs an electron accelerator to create a bremsstrahlung cone, which after collimation strikes a sample and generates positrons in the sample volume via pair production. The depth that positrons are produced at is controlled by the 'range' of the bremsstrahlung photons and depends on photon energy and the medium. There are no photon-induced activation or positron emitters involved in AG-PAS. The annihilation photons are recorded by a high resolution $\mathrm{HPGe}$ detector and the Doppler broadening analysis of the $511 \mathrm{keV}$ peak is performed to determine shape parameters: $S$ - area under the central region of the peak over the total area, $W$ - area under the wings over the total area and $T-$ ratio of $W$ over $S$. This approach creates a possibility to add defect density imaging capabilities of large scale engineering materials to the conventional PAS techniques, because it combines high penetration of $\mathrm{MeV}$ gamma rays with the high sensitivity of positrons to microscopic defects.

We have begun investigating this new potential of the technique. The work presented here serves as the first step in this direction. We employed steel tensile specimens prepared at the department of mechanical engineering of UNLV to demonstrate the sensitivity of our technique to different degrees of mechanical damage. We also tested sample and measurement reproducibility. The main limitation of the AG-PAS experiments performed in the past [4-6] was the low repetition rate of the LINAC $(200-300 \mathrm{~Hz})$, while the 
current experiments were performed by using a $1 \mathrm{kHz}$ High Repetition Rate LINAC (HRRL), which makes defect density imaging with AG-PAS more feasible.

\section{METHODS AND MATERIALS}

\section{Experimental Setup}

A $15 \mathrm{MeV}$ electron beam from the HRRL was bent $90^{\circ}$ before striking a $1 \mathrm{~mm}$ thick tungsten converter. The accelerator was running with 30 ns pulses, 1-2 $\mathrm{mA}$ peak current at $1 \mathrm{kHz}$ repetition rate. The bremsstrahlung cone was filtered by a $20 \mathrm{~cm}$ thick graphite hardener to increase the contribution of the high energy photons in the spectrum. The hardened beam went through a $1.2 \mathrm{~m}$ thick concrete wall that had two collimators. The primary collimator was a 25 $\mathrm{cm}$ long steel cylinder with a $6 \mathrm{~mm}$ diameter hole in the center. The secondary (clean up) collimator was a $2.54 \mathrm{~cm}$ diameter hole in a $15 \mathrm{~cm}$ thick lead cylinder. The well-collimated and filtered beam then struck our steel specimens. The experimental setup is schematically presented in FIGURE 1.

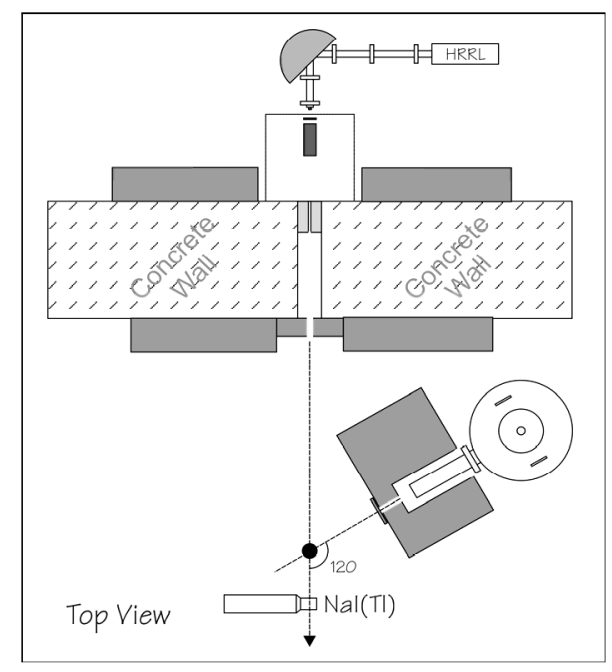

FIGURE 1. Schematic illustration of the experimental setup

Compton scattering and lead XRF lines predominantly contributed to the low energy region of the detected spectra, while pair production created positrons throughout the sample volume, resulting in emission of $511 \mathrm{keV}$ gammas. The spectra emitted from the specimens were recorded by a heavily shielded, $20 \%$ relative efficiency HPGe detector. The orientation of the detector was such that there was a $120^{\circ}$ angle between the beam line and the detector field of view. The shielding was made of lead bricks and had the following dimensions: $30 \mathrm{~cm}$ thick on the wall side, $20 \mathrm{~cm}$ thick on the opposite side and $10 \mathrm{~cm}$ thick in front, top and bottom. The detector was placed behind a $2.54 \mathrm{~cm}$ collimator that was covered with a secondary $2.54 \mathrm{~cm}$ thick steel hardener to reduce the low energy background even further. Both, accelerator and detector sides of the concrete wall were also shielded with $20 \mathrm{~cm}$ thick lead to reduce the scattered photons coming from the beam. Stability of the accelerator intensity was monitored by a NaI(T1) detector. The signal from the $\mathrm{NaI}(\mathrm{Tl})$ detector was used to gate the germanium detector so we could only record the events associated with the accelerator pulses. $1 \mu \mathrm{Ci}{ }^{133} \mathrm{Ba}$ and ${ }^{137} \mathrm{Cs}$ sources were employed for calibration and gain shift monitoring purposes.

\section{Steel Specimens}

We used pristine and mechanically damaged (stretched) steel tensile specimens in our experiments. The pristine specimens were made of P91 grade stainless steel, which is modified $9 \mathrm{Cr} 1 \mathrm{Mo}(9 \% \mathrm{Cr}$ and $1 \% \mathrm{Mo}$ ). We had two sets of P91 grade samples with different $\mathrm{Si}$ levels: 9Cr1Mo-SiA - 0.5\% Si and 9Cr1Mo-SiB $-1.5 \%$ Si. The damaged samples were $304 \mathrm{~L}$ grade stainless steel specimens stressed with three different loads. The applied loads - 2500 lbsforce, $3200 \mathrm{lbs}$-force and $4000 \mathrm{lbs}$-force were chosen such that they fell between the Yield Strength (2177 lbs-force) and the Ultimate Tensile Strength (4695 lbsforce) on the stress-strain curve of the $304 \mathrm{~L}$ specimens. All the samples had the following dimensions: overall length -4 inches $(10.16 \mathrm{~cm})$, gage length -1 inch $(2.54 \mathrm{~cm})$ and gage diameter -0.25 inch $(6.35 \mathrm{~mm})$.

\section{Data Analysis}

The data was recorded in a list (event by event) mode from three ADC's - gated HPGe spectrum, notgated HPGe spectrum and NaI(Tl) spectrum. First, list files were converted to text format and then analyzed by two FORTRAN codes. The first one transformed the text files into a histogram form while the second one used these histogram files as input and performed peak search, background subtraction and gain stabilization, set proper windows for the center and wing regions of the 511 peak, and finally calculated $S$, $W$ and $T$ parameters.

\section{RESULTS AND DISCUSSIONS}

Experiments were run at $25-30 \%$ pile-up level, which meant 250-300 total counts/sec on the gated germanium spectrum. The counting rate of the $511 \mathrm{keV}$ peak at this pile-up was about $8-10$ counts/s. Data acquisition time for each run was 2 hours. Each 511 
keV peak we analyzed for $S-T-W$ had $5 \cdot 10^{4}-6.5 \cdot 10^{4}$ counts which gave us sufficient statistics. A typical gated HPGe spectrum is presented in FIGURE 2. It's evident that photo-electric and Compton scattering processes dominate in the low energy region of the spectrum, which result in XRF peaks from lead shielding and background photons scattered into the detector. The Compton edge of the $511 \mathrm{keV}$ is visible at about $340 \mathrm{keV}$. The four ${ }^{133} \mathrm{Ba}$ peaks and the ${ }^{137} \mathrm{Cs}$ peak are also present.

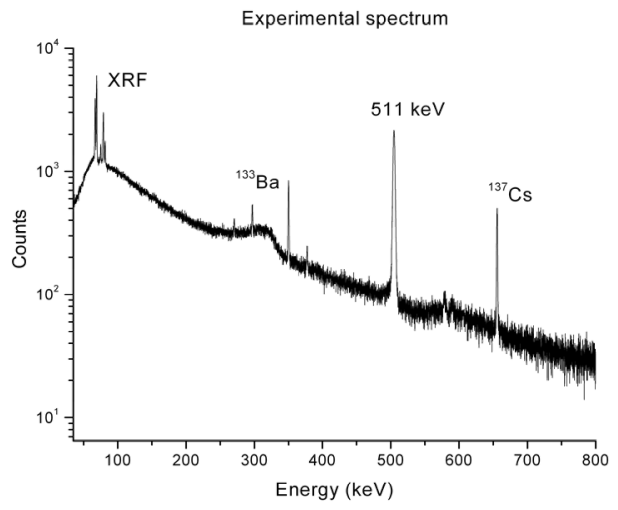

FIGURE 2. Gated HPGe spectrum acquired by counting for 2 hours.

FIGURE 3 and FIGURE 4 demonstrate sample reproducibility test results for $9 \mathrm{Cr} 1 \mathrm{Mo}-\mathrm{SiA}$ and $9 \mathrm{Cr} 1 \mathrm{Mo}-\mathrm{SiB}$ specimens respectively. Solid horizontal lines represent the test mean of the sample, while dashed lines are $95 \%$ confidence limits of the population (true) mean obtained from T-test analysis. The results are consistent with each other in both data sets.

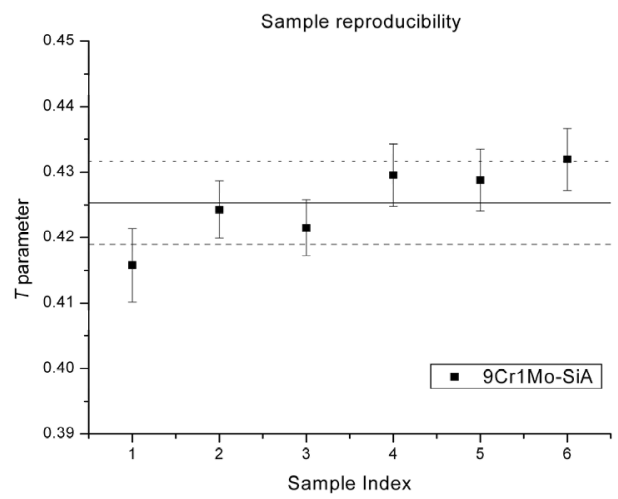

FIGURE 3. $T$ parameters for six identical pristine tensile specimens made of $9 \mathrm{Cr} 1 \mathrm{Mo}-\mathrm{SiA}(0.5 \% \mathrm{Si})$ steel. Note: the solid horizontal line is the test mean, while dashed lines represent $95 \%$ confidence limits of the true mean.

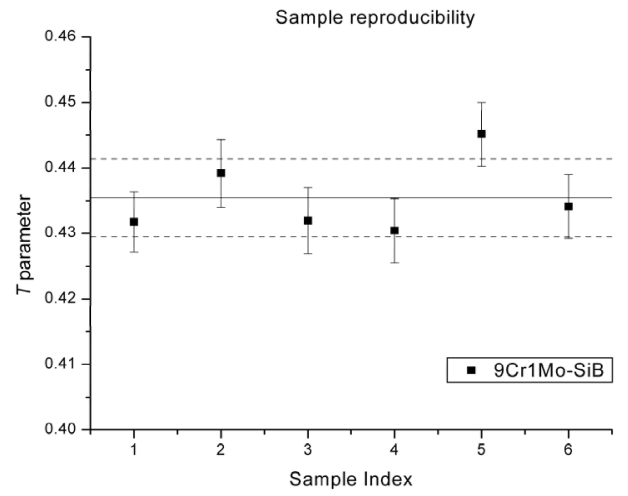

FIGURE 4. $T$ parameters for six identical pristine tensile specimens made of $9 \mathrm{Cr} 1 \mathrm{Mo}-\mathrm{SiB}(1.5 \% \mathrm{Si})$ steel. Note: the solid horizontal line is the test mean, while dashed lines represent $95 \%$ confidence limits of the true mean.

FIGURE 5 was generated to examine the measurement reproducibility of each damaged 304L steel specimens. In another words, this was an attempt to demonstrate if this technique produces the same results by counting the same samples number of times. It also shows the ability of AG-PAS to differentiate different levels of defect densities. $T$ parameter drops with the increasing load because $S$ parameter increases. Higher load means more defect concentration and consequently more trapped positrons, annihilating predominantly with valance electrons, which results in higher $S$. Again, solid lines are test mean values while dashed lines are 95\% confidence intervals for true mean. Even though we only have 3-4 data points per set of runs, the results indicate that data sets with the same sample are statistically consistent and $T$ parameters for those specimens damaged with different loads are distinguishable.

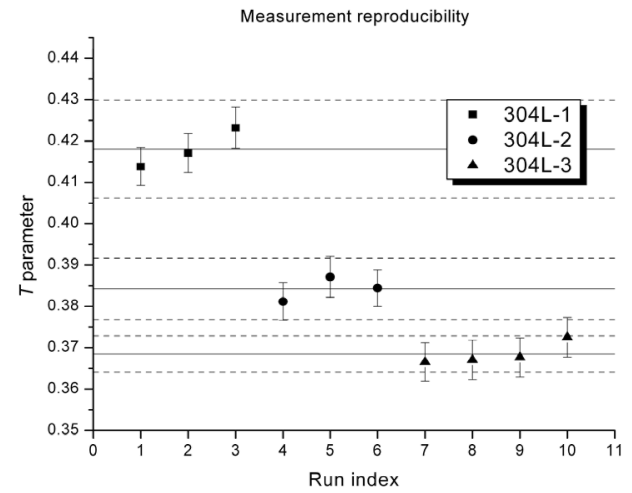

FIGURE 5. $T$ parameters of $304 \mathrm{~L}$ steel tensile specimens damaged with different loads and measured number of times. 304L-1 corresponds to 2500 lbs-force of load; 304L-2 corresponds to $3200 \mathrm{lbs}$-force and 304L-3 - $4000 \mathrm{lbs}$-force. 
FIGURE 6 displays averages for each data set to summarize all the results. It would have been more complete comparison if we had pristine 304L samples, but the data points presented on this graph still clearly demonstrate that $T$ parameter calculated based on our experimental technique has enough sensitivity to identify specimens with different defect densities. This makes AG-PAS a promising and feasible tool for defect density mapping of large scale engineering materials.

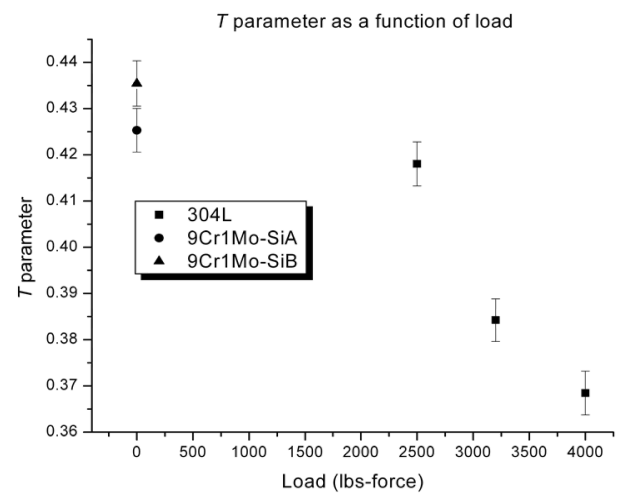

FIGURE 6. Average values of $T$ for each data set. Note that damaged specimens were a different alloy than undamaged and, therefore, the zero-load specimens may not represent the zero-load $T$ value for $304 \mathrm{~L}$

\section{CONCLUSIONS}

AG-PAS experiments were conducted to perform $S-T-W$ analysis of pristine $\mathrm{P} 91$ grade and mechanically damaged 304L grade steel tensile specimens. We have demonstrated reproducibility of sample preparation and AG-PAS experimental analysis. More experiments are needed to obtain better statistics and better understanding of system optimization. Nevertheless, the results revealed that the technique sensitively distinguishes specimens damaged with different loads. Future work will include feasibility study of 3D defect density imaging.

\section{ACKNOWLEDGMENTS}

This work was funded by a grant from DOE \# DE-FC07-Q6ID14780

\section{REFERENCES}

1. P. Hautojarvi, Positrons in Solids. Topics in Current Physics, edited by P. Hautojarvi (Springer, Berlin 1979), Vol. 12

2. Y. K. Park, J. T. Waber, M. Meshii, C.L. Snead, Jr. and C.G Park, Phys. Rev. B. 34, pp. 823-836 (1986)

3. T. Wider, K. Maier and U. Holtzwarth, Phys. Rev. B. 60, pp. 179-190 (1999)

4. F. A. Selim, D. P. Wells, J. F. Harmon, W. Scates, J. Kwofie, R. Spaulding, S. P. Duttagupta, J. L. Jones, T. White and T. Roney, Nucl. Instr. and Meth.B 192, (2002) 197

5. F. A. Selim, D. P. Wells, J. F. Harmon, J. Kwofie, G. Erikson and T. Roney, Radiat. Phys. Chem. 68, pp. 427$430(2003)$

6. F. A. Selim, D. P. Wells, J. F. Harmon, J. Williams, J. Appl. Phys. 97, 113539 (2005) 